\title{
Surface modification of Raw and Frit glazes by non-thermal helium plasma jet
}

\author{
M. Ghasemi ${ }^{1}$ F. Sohbatzadeh ${ }^{1,2} \cdot$ S. Mirzanejhad ${ }^{1,2}$
}

Received: 13 March 2015/Accepted: 27 April 2015/Published online: 4 June 2015

(c) The Author(s) 2015. This article is published with open access at Springerlink.com

\begin{abstract}
In this study, non-thermal atmospheric pressure plasma jet (APPJ) was utilized to improve the adhesion of Raw and Frit glazes. These glazes are widely used in industry to make chinaware, decorative dishes and tiles applied at wall and floor. As they should be painted before use, increasing their adhesive properties leads to a better paint durability. Electrical and optical characteristics of the plasma jet are investigated to optimize for efficient treatment. Contact angle measurement and surface energy calculation demonstrate a drastic increase after the plasma treatment indicating wettability and paintability enhancement. Moreover, atomic force microscopy and X-ray photoelectron spectroscopy analyses were performed on the specimens to explore the influence of helium plasma jet on the physical and chemical properties of the glazes, microscopically. AFM analysis reveals surface etching resulted from the bombardment of the solid surfaces by the APPJ using helium fed gas. The process aims to enhance adhesive properties of glaze surfaces.
\end{abstract}

Keywords Adhesion - Plasma jet $\cdot$ Surface modification

F. Sohbatzadeh

f.sohbat@umz.ac.ir

1 Department of Atomic and Molecular Physics, Faculty of Basic Sciences, University of Mazandaran, 47416-95447 Babolsar, Iran

2 Nano and Biotechnology Research Group, Faculty of Basic Sciences, University of Mazandaran, 47416-95447 Babolsar, Iran

\section{Introduction}

Some materials such as polymers, textiles and metals, which are widely used in industrial and medical applications, have low surface free energy. This limitation restricts them as it leads to poor wettability, poor adhesion and poor printability, so they require surface modification to be more efficient. Among conventional methods of surface modification, atmospheric pressure plasma processing has attracted great interests due to its numerous advantages over the traditional processes $[1,2]$. Atmospheric pressure plasma surface activation is an environmentally friendly method as it does not require the use of water and chemicals which leads to pollutants and corresponding cost for effluent treatment [3]. Furthermore, non-thermal plasma is a suitable choice for heat-sensitive materials and there is no need for vacuum equipment which increases the cost. Production of a large variety of chemically active functional groups makes it fast, effective and versatile technique for surface activation.

Noh et al. [2] employed $\mathrm{O}_{2}$ APPJ as a second step of treatment of Polytetrafluoroethylene (PTFE) after chemical treatment. PTFE is extensively utilized in synthetic vascular surgery and medical devices because of its chemical and mechanical stability, but it is limited due to lack of haemocompatibility. APPJ is a suitable choice as it could improve cellular interaction property and tailor the biological response to the implant. Sorrentino and Carrino demonstrated that an oxygen cold plasma treatment could improve wettability and adhesion of Al2024 surface which is an important alloy at aeronautical application. It should be painted to prevent corrosion which is caused by aeronautical critical environmental condition. They also investigated the influence of different parameters of plasma on the durability of paint on its surface [4]. The plasma 
processing results in physical and chemical modification in scale of several nanometres (first few molecular layers) while maintaining the properties of the bulk unchanged [3]. There are many investigations, in which plasma was utilized to improve surface properties of materials such as polymers, textiles and etc. Their physical and chemical properties after plasma treatment were examined in detail as well. But there are a few studies investigated the effect of plasma on the properties of non-carbonic base surfaces and needs more investigations [1-10]. The aim of this paper is to utilize atmospheric pressure helium plasma jet on Raw and Frit glaze surfaces to improve their paintability and explore the effect of the plasma on their surface properties which seems not fully understood so far. Helium, in comparison with other gases, could be considered the most convenient gas working at atmospheric pressure, as it allows stabilizing homogeneous glow discharges at lower sustaining voltages and inter-electrode gaps. It is also very suitable for surface treatment because of low degradation effect and high properties of cross linking and functionalizing on to the surface [8, 10]. We used helium plasma as it is capable of maintaining simultaneous stability and reactivity, while in other inert gases chemical reactivity is obtained by adding a small amount of reactive gases at the expense of stability and increasing the temperature which may cause non-uniform processing.

\section{Materials and methods}

The atmospheric pressure plasma jet used in this study was single electrode configuration based on DBD principle of operation. The image of the cold helium plasma jet is presented in Fig. 1. The plasma tube consists of $10 \mathrm{~mm}$ capillary quartz of inner and outer diameter of 1 and $3 \mathrm{~mm}$, respectively, around which a ring cupper electrode of $10 \mathrm{~mm}$ length and $50 \mu \mathrm{m}$ thickness was wrapped $10 \mathrm{~mm}$ from its end. 0.5-1 standard litre per minute (SLM) of helium gas with $99.999 \%$ purity was flourished inside the capillary tube. A home-built AC sinusoidal power supply at the frequency of 10 and $19 \mathrm{kHz}$ was applied to ignite the plasma jet.

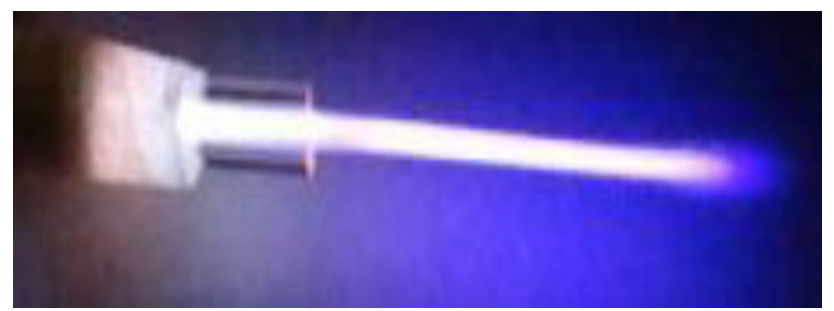

Fig. 1 Image of the cold helium plasma jet at atmospheric pressure utilized for surface activation of glazes
To explore the plasma capabilities, V-I characteristics and optical emission spectra (OES) were investigated. Applied voltage and jet current were measured using a high voltage probe (Tektronix P6015 A) and a current probe (Tektronix TCPA-300). Optical emission spectroscopy was used to detect plasma effective species produced by helium APPJ responsible for plasma processing. We used S100 spectrometer (Solar laser Systems) which covers 200$1100 \mathrm{~nm}$ with the resolution of $1 \mathrm{~nm}$. Microscopic properties of the glaze surfaces were analysed using atomic force microscopy (Quto Probe, Cp, USA, Contact), and Xray photoelectron spectroscopy (Aluminium Monochromated XPS $\mathrm{h} \vartheta-1486.6 \mathrm{eV}$ ) was used to reveal the surface chemical change caused by the plasma jet.

Voltage and current curves are shown in Fig. 2. There is at least one current spike every half cycle of the voltage which occurs at fixed positions of each cycle. It is known as bullet mode which is suitable for surface treatment as it provides uniform treatment $[11,12]$.

Two types of glazes selected to improve their paintability are Raw and Frit glazes. These glazes are widely used in industry to make chinaware, decorative dishes and tiles utilized at wall and floor. As both of them need to be painted before use, the activation of their surfaces improves their paintability (paint absorption) and enhances their efficiency (paint durability is an important factor of a good earthenware or tile). Table 1 represents the compositions of Raw and Frit glazes and their percentages. Raw and Frit glazes were cut into pieces of $8 \times 8 \mathrm{~mm}^{2}$ and $9 \times 11 \mathrm{~mm}^{2}$, respectively, to be able to use for XPS and AFM analyses. Before the plasma treatment, the specimens were cleaned to remove their surface contaminations. To prepare the samples, they were cleaned ultrasonically in isopropanol for $1 \mathrm{~min}$, then rinsed with fresh isopropanol again and dried out under nitrogen flow. After cleaning, the specimens were treated by the cold helium APPJ. AC sinusoidal high voltage power supply at the frequency of

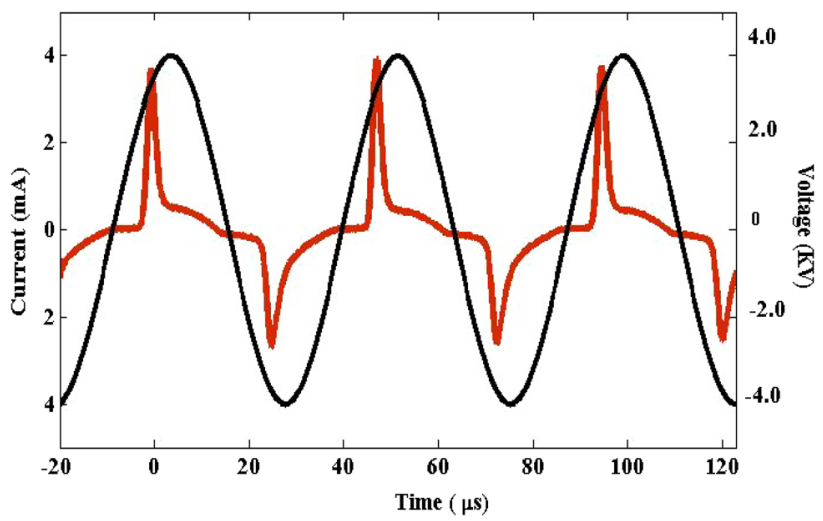

Fig. 2 Voltage and current curves measured at downstream electrode at the frequency of $19 \mathrm{kHz}$ and applied voltage of $4 \mathrm{kV}$ 
Table 1 Compositions of Frit and Raw glazes

\begin{tabular}{lllllllllllll}
\hline Oxide $(\%)$ & $\mathrm{CaO}$ & $\mathrm{Na}_{2} \mathrm{O}$ & $\mathrm{ZnO}$ & $\mathrm{K}_{2} \mathrm{O}$ & $\mathrm{Al}_{2} \mathrm{O}_{3}$ & $\mathrm{Fe}_{2} \mathrm{O}_{3}$ & $\mathrm{SiO}_{2}$ & $\mathrm{~B}_{2} \mathrm{O}_{3}$ & $\mathrm{TiO}_{2}$ & $\mathrm{ZrO}_{2}$ & $\mathrm{MgO}$ & $\mathrm{BaO}$ \\
\hline Frit & 9.03 & 0.19 & 10.69 & 2.23 & 6.74 & 0.40 & 49.1 & 5.80 & 0.03 & 13.95 & 2.84 & - \\
Raw & 8.45 & 0.92 & 6.13 & - & 12.54 & 0.36 & 61.01 & - & 0.14 & - & 3.01 & 5.77 \\
\hline
\end{tabular}

10 and $19 \mathrm{kHz}$ was used to ignite the plasma. The applied voltages of 4 and $14 \mathrm{kV}$ were used for Raw and Frit glazes, respectively. 0.5 SLM helium gas was passed through the plasma tube, and glazes were exposed to the plasma jet for $1 \mathrm{~min}$ at the distance of $3 \mathrm{~mm}$ from the capillary end. It is worth noting that 1-min treatment is not a long time with regard to the size of the glazes and the jet cross section.

\section{Plasma optical emission}

Optical emission spectroscopy is a powerful technique to determine optical characteristics of the plasma. Identification of the plasma reactive species responsible for relevant application enables one to enhance plasma efficiency by making it optimum. The optical fibre probe was placed $3 \mathrm{~mm}$ below the exit of the quartz tube where the helium flow is mixed with the ambient air to produce reactive species. Figure 3 demonstrates the optical emission spectral lines of helium plasma jet with the key lines labelled. Colliding of energetic electrons produced at the discharge tube with the background helium atoms causes the production of excited and metastable helium atoms which play

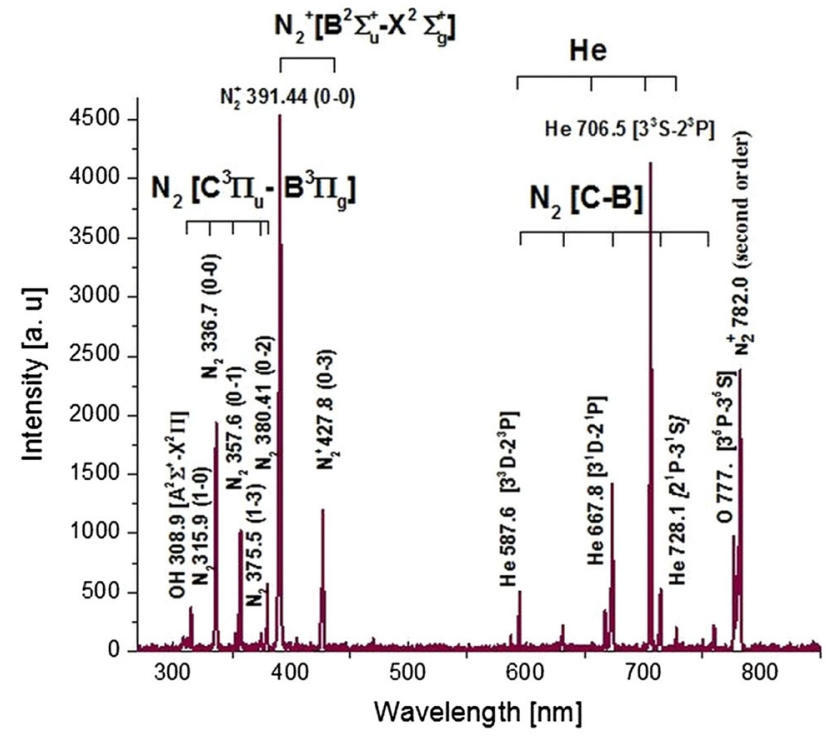

Fig. 3 Optical emission lines of helium plasma jet at $3 \mathrm{~mm}$ below the exit of the quartz tube. The spectral lines and their transition levels are labelled in the spectrum an important role initiating many chemical reactions inside the plasma tube [11]:

$\mathrm{He}+\mathrm{e} \rightarrow \mathrm{He}^{*}(2 \mathrm{p})+\mathrm{e}$

$\mathrm{He}+\mathrm{e} \rightarrow \mathrm{He}^{*}(2 \mathrm{~S})+\mathrm{e}$

Helium line of $706 \mathrm{~nm}\left[3^{3} \mathrm{~S} \rightarrow 2^{3} \mathrm{P}\right]$ with the threshold energy of $22.7 \mathrm{eV}$ is an indicator of the energetic electron [13] which is the second intense spectral line at the plasma jet emission spectrum shown in Fig. 3. The other helium atomic lines observed in Fig. 3 are $587.6\left(3^{3} \mathrm{D} \rightarrow 2^{3} \mathrm{P}\right)$, $667.8\left(3^{1} \mathrm{D} \rightarrow 2^{1} \mathrm{P}\right)$ and $728.1\left(3^{1} \mathrm{~S} \rightarrow 2^{1} \mathrm{P}\right)$. A helium atom naturally has two metastable levels, which are $2^{1} \mathrm{~S}_{0}$ (singlet) and $2^{3} S_{1}$ (triplet) with the energies of 19.8 and $20.6 \mathrm{eV}$, respectively $[8,13]$. Helium metastable lines are reported at $\mathrm{He}^{*} 501.6 \mathrm{~nm}\left(3^{1} \mathrm{P} \rightarrow 2^{1} \mathrm{~S}\right)$ and $\mathrm{He}_{2}^{*} 388.86$ $\left(3^{3} \mathrm{P}_{2} \rightarrow 2^{3} \mathrm{~S}_{1}\right)$ [13]. Highly energetic helium metastable atoms are able to ionize the nitrogen through the penning ionization due to the interaction with the ambient air [11].

$$
\begin{aligned}
\mathrm{He}^{*}+N_{2} \rightarrow & r N_{2}^{+}\left(B^{2} \sum_{u}^{+}\right)+(1-r) N_{2}^{+}\left(X^{2} \sum_{g}^{+}\right)+\mathrm{He} \\
& +e
\end{aligned}
$$

$$
\begin{aligned}
\mathrm{He}_{2}^{*}+N_{2} \rightarrow & r N_{2}^{+}\left(B^{2} \sum_{u}^{+}\right)+(1-r) N_{2}^{+}\left(X^{2} \sum_{g}^{+}\right) \\
& +2 \mathrm{He}+e
\end{aligned}
$$

It is well known that nitrogen molecules are very effective in quenching the helium metastables [17]. Rapid penning reaction reduces the effective lifetime of helium metastables and produces excited nitrogen species [11]. $\mathrm{N}_{2}$ second positive system $\left(C^{3} \prod_{u} \rightarrow B^{3} \prod_{g}\right)$ is observed at helium spectrum (Fig. 3) due to the existence of air at the two wavelength intervals of (315-381) and (590-770) in which the intense peaks are observed at the wavelengths of $315.9(1-0), 336.7$ (0-0), $357.6(0-1), 375.5(1-3)$ and $380.41(0-2)$. Moreover, radiative dissociation, which takes place after recombination process, could lead to the decrease of $\mathrm{He}_{2}^{*}$ population according to the following reactions [15]

$\mathrm{He}^{*}+2 \mathrm{He} \rightarrow 2 \mathrm{He}^{*}+\mathrm{He}$

$\mathrm{He}_{2}^{*} \rightarrow 2 \mathrm{He}+\mathrm{h} \vartheta$

It is possible that nitrogen second positive emission is capable of producing a great amount of seed electron for subsequent discharge events. It is reported that nitrogen has 
a crucial role in producing $\mathrm{N}_{4}^{+}$by penning interaction between two nitrogen molecules to maintain a stable glow discharge [14].

$N_{2}\left(a^{1} \sum_{u}^{-}\right)+N_{2}\left(A^{3} \sum_{u}^{+}\right) \rightarrow N_{4}^{+}+e$

$N_{2}\left(a^{1} \sum_{u}^{-}\right)+N_{2}\left(A^{1} \sum_{u}^{-}\right) \rightarrow N_{4}^{+}+e$

There are also several sources of electron such as the following reactions $[15,16]$ :

$\mathrm{He}^{*}+\mathrm{He}^{*} \rightarrow \mathrm{He}^{+}+\mathrm{He}+\mathrm{e}$

$\mathrm{He}_{2}^{*}+\mathrm{N}_{2} \rightarrow \mathrm{N}_{2}^{+}+2 \mathrm{He}+\mathrm{e}$

$\mathrm{He}_{2}^{*}+\mathrm{He}_{2}^{*} \rightarrow \mathrm{He}^{+}+2 \mathrm{He}+\mathrm{e}$

Other positive ions are also produced in contact with nitrogen such as $\mathrm{He}^{+}, \mathrm{He}_{2}^{+}, \mathrm{N}^{+}, \mathrm{N}_{3}^{+}$and $\mathrm{N}_{4}^{+}$. Two intense spectral lines of $\mathrm{N}_{2}^{+}$first negative system $\left(\sum_{u}^{+} \rightarrow X^{2} \sum_{g}^{+}\right)$ at the wavelengths of 391.44 and $427.8 \mathrm{~nm}$ and a spectral line of $\mathrm{N}_{2}^{+}$second-order system at the wavelength of 782.0 are the other prominent productions of the discharge. $\mathrm{N}_{2}^{+}$is the dominant ion in the plasma jet reported in both numerical and experimental investigations [14-17]. $\mathrm{N}_{2}^{+}$ line at $391.4 \mathrm{~nm}$, which is well known as an indicator of helium metastable presence, is the intense line in the jet spectrum presented in Fig. 3. Oxygen $3^{5} \mathrm{P} \rightarrow 3^{5} \mathrm{~S}$ at $777.4 \mathrm{~nm}$ and $\mathrm{OH}\left[A^{2} \sum^{+} \rightarrow X^{2} \prod\right]$ at $308 \mathrm{~nm}$ are the other discharge productions both present at the result of water vapour dissociation [15]. They are also labelled in Fig. 3.

$$
\begin{aligned}
& \mathrm{H}_{2} \mathrm{O}+\mathrm{e} \rightarrow \mathrm{OH}+\mathrm{H}+\mathrm{e} \\
& \mathrm{O}_{2}+\mathrm{e} \rightarrow \mathrm{O}+\mathrm{O}+\mathrm{e}
\end{aligned}
$$

Three-body collisions occurred in the plasma state can lead to the quenching of atomic oxygen and reducing the oxygen emission intensity.

$\mathrm{He}+\mathrm{O}+\mathrm{O} \rightarrow \mathrm{He}+\mathrm{O}_{2}$

$\mathrm{He}+\mathrm{O}_{2}+\mathrm{O} \rightarrow \mathrm{He}+\mathrm{O}_{3}$

Formation of such intense reactive species in helium as an inert gas is beneficial for atmospheric pressure plasma application especially plasma processing. Dr Walsh et al. demonstrated that in bullet mode of helium plasma, the nitrogen emission is in the direction of the plasma plume extension towards the downstream electrode. The plasma bullet front is largely made of highenergy electrons with a cloud of positive nitrogen ions located at a short distance behind the electron region [11].

\section{Wettability measurement}

Surface reactivity is characterized by water wettability which describes the ability of a liquid to spread over and penetrate into a surface and is measured by the contact angle between the liquid and the surface. In general, contact angle analysis is a surface-sensitive technique which allows the wetting properties and surface energy of the investigated sample to be measured. In this study, deionised distilled water droplet of 0.1 micro litre dispersed on the glaze surfaces; the pictures were captured as quickly as possible after placing the droplets on the surfaces. Dino Lite Digital Microscope (200X-ANMO Electronics Co.) was used to capture the image and the contact angles were measured using its software. The results of averaged contact angle measurements and their standard deviations are shown in Table 2. It should be noted that the averaged results were obtained after 15 times repeated tests. Similar measurements were repeated for Frit glaze. Figure 4 shows the image of water droplet on the Frit glaze surface before (4a) and after (4b) the cold APPJ treatment.

Surface free energy (SFE) indicates chemical reactivity and compatibility with adhesives, paints and inks. It is one of the thermodynamic quantities describing the equilibrium state of atoms in the surface layer of materials. In other words, it reflects the imbalance of intermolecular interactions at the phase boundary of two mediums and defines as a work necessary to create a new surface unit, at equilibrium separation of two phases in reversible isothermal processes. SFE is an indicator of adhesive properties which plays an important role in the processes of adhesion $[1,18]$. The methods of calculation of SFE is from the contact angle measurements and based on Young equation which was derived from the equilibrium condition of forces representing surface tensions at the contact point of three phases of solid, liquid and gas. The energy equivalent of the Young equation is as follows $[1,18]$ :

$\gamma_{L}(\cos \theta)=\gamma_{S}-\gamma_{S L}$

where $\gamma_{S}$ denotes the SFE of solid in vacuum, $\gamma_{S L}$ is the surface tension on the solid-liquid phase boundary, $\gamma_{L}$

Table 2 Contact angles of water and diiodomethane dispersed on the Frit and Raw glazes

\begin{tabular}{llllll}
\hline Glaze & Liquid & $\theta_{n t}$ & Sdev & $\theta_{t}$ & Sdev \\
\hline Frit & Water & 87.78 & 3.86 & 12.33 & 4.41 \\
& Diiodomethane & 51.40 & 2.78 & 59.37 & 3.46 \\
\multirow{2}{*}{ Raw } & Water & 94.66 & 3.83 & 11.44 & 4.82 \\
& Diiodomethane & 53.72 & 6.67 & 63.70 & 2.82
\end{tabular}


Fig. 4 The picture of water droplet on the Frit glaze surface before (a) and after (b) the plasma jet treatment
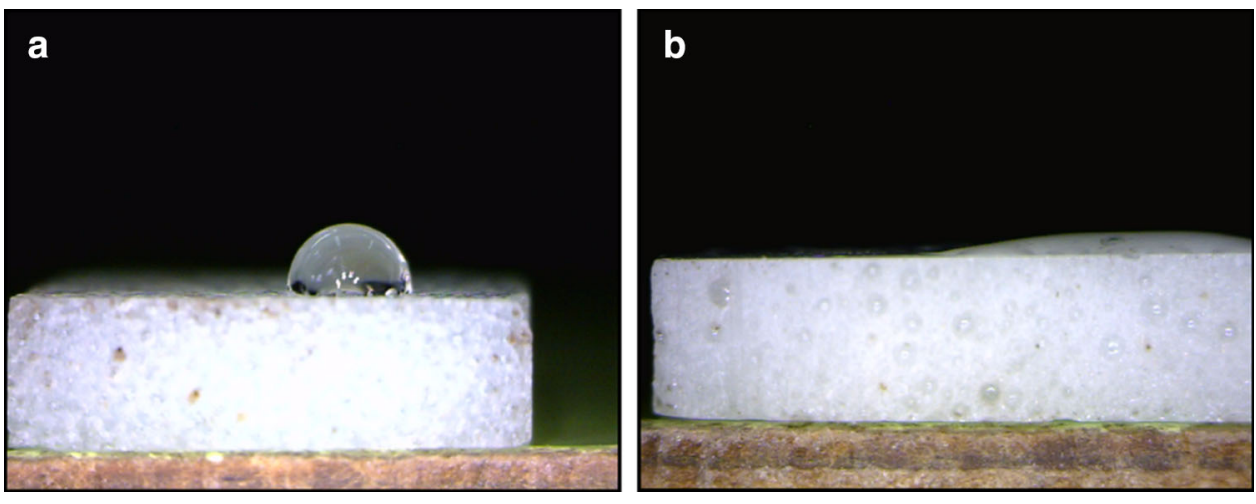

represents the SFE of the measured liquid, and $\theta$ is the contact angle that should be measured. In this paper, we used the Owens-Wendt method which considered two components of dispersion and polar SFE. It is based on Berthelot hypothesis which considered the geometric mean of intermolecular interactions within each substance as the interactions present in their surface layers. Combining this equation with Young's equation, the following geometric mean equation is obtained [18]

$\gamma_{L}(1+\cos \theta)=2\left(\sqrt{\gamma_{s}^{d} \gamma_{L}^{d}}+\sqrt{\gamma_{s}^{p} \gamma_{L}^{p}}\right)$

Note that the total SFE is the sum of the two dispersive and polar components [18]

$\gamma_{s}=\gamma_{s}^{d}+\gamma_{s}^{p}$

Because of the presence of the polar term, the number of liquids required to calculate the solid surface components is two of known surface tension [1,18-20]. One should be polar and the other should be non-polar. Distilled water with the surface energy of $72.8 \mathrm{mN} / \mathrm{m}\left(\gamma_{w}^{d}=21.8, \gamma_{w}^{p}=\right.$ 51.0) and diiodomethane (Merck Schuchardt OHG, 85662 Hohenbrunn, Germany) with the surface energy of 50.8 $\mathrm{mN} / \mathrm{m}\left(\gamma_{d}^{d}=50.8, \gamma_{d}^{p}=0.0\right)$ were chosen as the two polar and non-polar liquids to measure the SFE of the glazes [20]. The contact angles of these two liquids with Raw and Frit glazes are shown in Table 2, and the results of their SFE are shown in Table 3.

Table 3 Surface free energy of Frit and Raw glazes

\begin{tabular}{lrll}
\hline Glaze & $\gamma_{S}^{P}$ & $\gamma_{S}^{D}$ & $\gamma_{\text {total }}$ \\
\hline Frit (non-treated) & 2.3 & 33.5 & 35.8 \\
Frit (treated) & 43.0 & 29.1 & 72.1 \\
Raw (non-treated) & 1.0 & 32.2 & 33.2 \\
Raw (treated) & 45.3 & 26.5 & 71.8 \\
\hline
\end{tabular}

\section{Morphology and surface chemical analyses}

The physical modification of Frit glaze surface was investigated by atomic force microscopy technique (AFM). It will provide information about the morphology of the surface. Figure 5 represents the AFM image of Frit glaze surface at the scale of $5 \mu \mathrm{m}^{2}$ before (left side) and after the plasma treatment (right side). At the first glance, morphology of the Frit glaze surface changed significantly due to the bombardment of plasma ions, electrons and reactive species. The surface seems to be smoother after the plasma treatment. The data show a reduction in average roughness from 30.9 to 19.5 . Roughness is defined as the normalized standard deviation calculated from the local heights $\left(Z_{x-y}\right)$ and the average height $\left(Z_{\mathrm{av}}\right)$ determined over all $\mathrm{x}-\mathrm{y}$ coordinates $(N)$ measured in the AFM image. It should be noted that the result is the averaged number of data obtained from 6 different parts of the surface. It seems that the plasma removes a non-uniform layer in the scale of nanometre from the surface which made the surface smother with lower averaged roughness. It is likely etching.

X-ray photoelectron spectroscopy (XPS) reveals the surface chemistry changes of the surface after the plasma treatment. In Fig. 6, the chemical compositions of Raw glaze before and after plasma treatment are shown. Oxygen $1 \mathrm{~S}$ was the intense peak observed in the XPS spectrum.

\section{Results and discussion}

In this contribution, we used non-thermal helium plasma jet at atmospheric pressure to improve the adhesive properties of Raw and Frit glazes. The cold helium plasma jet used in this study is convenient for surface activation, as it is inexpensive and easy to use. We explored the electrical and optical characteristics of the plasma jet to achieve efficient treatment. Current measurement shows a stable mode of 
Fig. 5 AFM images of Frit glaze at the scale of $5 \mu \mathrm{m} \times 5 \mu \mathrm{m}$ before (left side) and after the plasma jet treatment (right side)
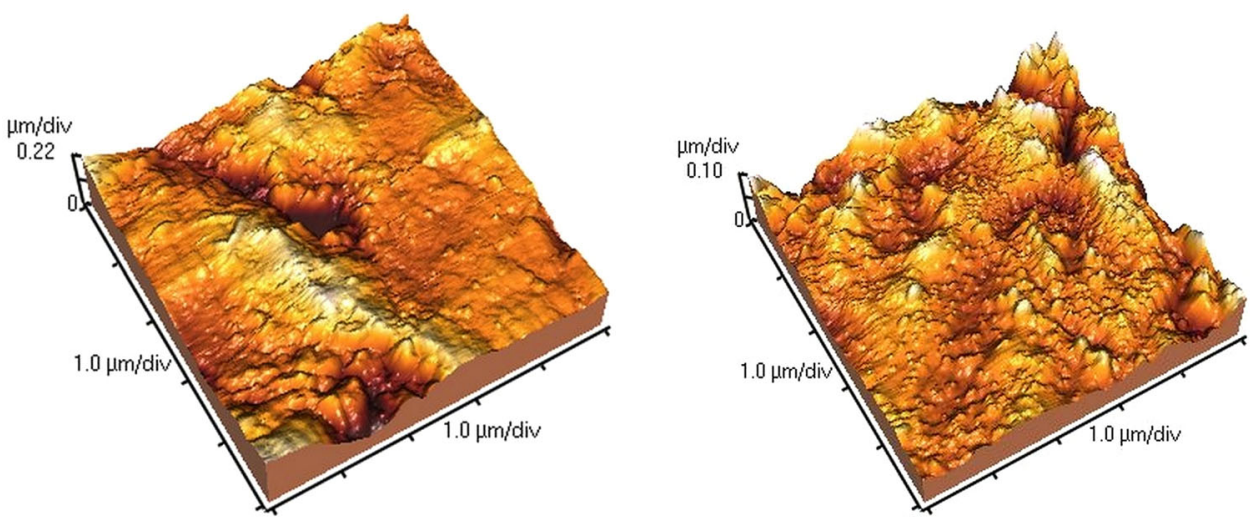

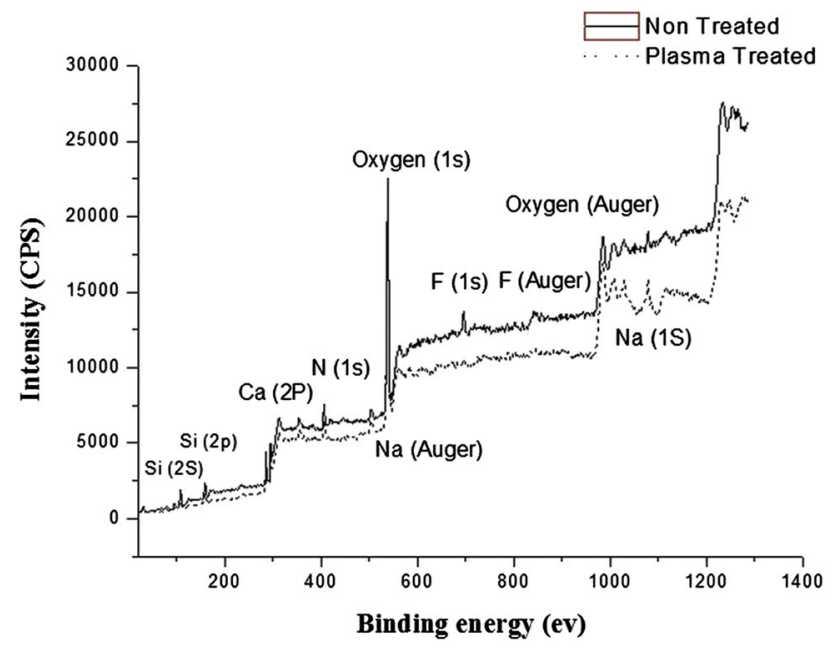

Fig. 6 XPS spectrum of Raw glaze before (solid line) compared with the case of plasma treatment (dot line)

helium plasma jet which could result in uniform treatment. Several reactive groups such as $\mathrm{N}_{2}$ second positive, $\mathrm{N}_{2}^{+}$first negative and second-order systems, atomic oxygen, helium atomic lines and $\mathrm{OH}$ line were observed at the helium emission spectrum. The indicator of the energetic metastable helium and energetic electrons, $\mathrm{N}_{2}^{+} 391.4 \mathrm{~nm}$ and $\mathrm{He}$ $706 \mathrm{~nm}$, respectively, are the first and second intense lines detected in the jet spectrum. The presence of the dominant well known helium plasma lines, $\mathrm{N}_{2}^{+}$and other reactive species of helium plasma already mentioned represents the plasma capability for surface modification.

Wettability and hydrophilicity of the specimens were examined by comparison of contact angles measured before and after the plasma treatment. The results and their standard deviations are shown in Table 2 as every contact angle reported is the averaged number of 15 times repeated tests. Water contact angles of both glazes are significantly decreased after treatment. Contact angle of $94.66^{\circ}$ for Raw glaze introduces it as a very hydrophobic surface before treatment, while reduction to $11.44^{\circ}$ could represent a huge improvement of the surface wettability and change into hydrophilic surface. Similar water contact angle reduction was measured for Frit glaze with negligible difference.

SFEs were calculated from contact angle of two, polar and non-polar, known liquids. Since it reflects chemical reactivity and compatibility with adhesives, paints and inks, it could be a good criteria of adhesive properties improvement result in better stick (attach or joint) to paint. SFE of the both glazes increased after plasma treatment which is attributed to the polar component of SFE resulted from plasma treatment. AFM and XPS analyses were performed to reveal the physical and chemical changes which led to increase in the contact angle and SFE of the glazes and consequently resulted in surface activation. Figure 5 demonstrates a significant change of the surface morphology due to the plasma treatment. The average roughness decreased and the surface seems to be smoother. AFM analyses, reported as a result of treatment of polymers and textiles by helium or mixture of helium and nitrogen, revealed the creation of granular structure on the surface at nanoscale domain and the change of surface roughness after the plasma treatment $[3,5,8,9,21]$. Examining the AFM images of different parts of surface reveals that, although the effect of plasma at different parts seems to be different apparently, all of them show that the plasma jet removes a nanoscale non-uniform layer from the surface and that a non-uniform etching process occurred. In other words, it is no matter whether the surface is composed of a small number of high peaks and valleys or a large number of them with moderate height. In both cases, the plasma removes a non-uniform layer. Consequently, the surface average roughness decreases by increasing the number of peaks and valley with lower height.

XPS analysis demonstrates the surface chemistry as shown in Fig. 6. Oxygen 1S was the intense peak observed in the XPS spectrum. The ratio of $\mathrm{O} / \mathrm{Si}$ increased from 11.95 to 13.61 after the plasma treatment which probably resulted in wettability improvement. Other prominent peaks observed such as $\mathrm{Si}(2 \mathrm{~S}), \mathrm{Si}(2 \mathrm{P}), \mathrm{N}(1 \mathrm{~S}), \mathrm{Ca}(2 \mathrm{P})$, 
$\mathrm{Na}$ (Auger), Oxygen (Auger), F (1S), F (Auger) and $\mathrm{Na}$ (1S) are labelled in Fig. 6. Moreover, the intensity level of the spectrum was decreased after plasma treatment, and the reduction does not happen at the same rate for different species.

Acknowledgments The authors would like to thank Mr. Hossein Ghassae, associate professor of Iranian University of Science and Technology, to make the glazes, Dr. Jun-Seok Oh for his kind help, Mr. Dave Atkinson for cutting the specimens, Prof. Piter Weightman and Mr. Paul Unsworth for XPS test from the University of Liverpool and also Mrs. Sahar Tayebtaher for AFM test from Materials and Energy Research Center of Iran.

Open Access This article is distributed under the terms of the Creative Commons Attribution 4.0 International License (http:// creativecommons.org/licenses/by/4.0/), which permits unrestricted use, distribution, and reproduction in any medium, provided you give appropriate credit to the original author(s) and the source, provide a link to the Creative Commons license, and indicate if changes were made.

\section{Reference}

1. Awaja, F., Gilbert, M., Kelly, G., Fox, B., Pigram, P.J.: Adhesion of polymers. Prog. Polym. Sci. 34(9), 948-968 (2009)

2. Noh, J.H., Baik, H.K., Noh, I., Park, J.C., Lee, I.S.: Surface modification of polytetrafluoroethylene using atmospheric pressure plasma jet for medical application. Surface Coat. Technol. 201(9), 5097-5101 (2007)

3. Geyter, N.De, Morent, R., Leys, C., Gengembre, L., Payen, E., Vlierberghe, S.V., Schacht, E.: DBD treatment of polyethylene terephthalate: atmospheric versus medium pressure treatment. Surface Coat. Technol. 202(13), 3000-3010 (2008)

4. Sorrentino, L., Carrino, L.: Influence of process parameters of oxygen cold plasma treatment on wettability ageing time of 2024 aluminum alloy. Int. J. Adhes. Adhes. 29(2), 136-143 (2009)

5. Noeske, M., Degenhardt, J., Strudthoff, S., Lommatzsch, U.: Plasma jet treatment of five polymers at atmospheric pressure: surface, modifications and the relevance for adhesion. Int. J. Adhes. Adhes. 24, 171-177 (2004)

6. Olszyna, A.R., Sokolowska, A., Kulakowska-pawlak, B., Dora, J.: Surface modification of $\mathrm{Al}_{2} \mathrm{O}_{3}-\mathrm{Cr}$ ceramic by non-isothermal $\mathrm{N}_{2}$ plasma treatment at atmospheric pressure. Plasma Proces. Polym. 4(1), S507-S511 (2007)

7. Sun, D., Stylios, G.K.: Fabric surface properties affected by low temperature plasma treatment. J. Mater. Process. Tech. 173, 172-177 (2006)
8. Borcia, G., Chiper, A., Rusu, I.: Using a $\mathrm{He}+\mathrm{N}_{2}$ dielectric barrier discharge for the modification of polymer surface properties. Plasm. Sour. Sci. Technol. 15(4), 849-857 (2006)

9. Wang, C.X., Ren, Y., Qiu, Y.P.: Penetration depth of atmospheric pressure plasma surface modification into multiple layers of polyester fabrics. Surface Coat. Technol. 202, 77-83 (2007)

10. Massines, F., Rabehi, A., Decomps, P., Ben Gadri, R., Segur, P., Mayoux, C.: Study of a glow discharge at atmospheric pressure controlled by dielectric barrier. J. Appl. Phys. 83(6), 2950-2957 (1998)

11. Walsh, J.L., Iza, F., Janson, N.B., Law, V.J., Kong, M.G.: Three distinct modes in a cold atmospheric pressure plasma jet. J. Phys. D: Appl. Phys. 43, Art. ID 075201, pp. 14 (2010)

12. Ghasemi, M., Olszewski, P., Bradley, J.W., Walsh, J.L.: Interaction of multiple plasma plumes in an atmospheric pressure plasma jet array. J. Phys. D: Appl. Phys. 46, Art. ID 052001, pp. 6 (2013)

13. Baldwin, K.G.H.: Metastable helium: atom optics with nanogrenades. Contemp. Phys. 46(2), 105-120 (2005)

14. Gherardi, N., Gouda, G., Gat, E., Ricard, A., Massines, F.: Transition from glow silent discharge to micro-discharges in nitrogen gas. Plasm. Sour. Sci. Technol. 9, 340-346 (2000)

15. Yuan, X., Raja, L.L.: Computational study of capacitively coupled high-pressure glow discharges in helium. IEEE Trans. Plasma Sci. 31(4), 495-503 (2003)

16. Deloche, R., Monchicourt, P., Cheret, M., Lambert, F.: Highpressure helium afterglow at room temperature. Phys. Rev. A. 13(3), 1140-1176 (1976)

17. Anghel, S.D., Simon, A., Radu, A.I., Hidi, I.J.: Nucl. Instrum. Methods Phys. Res. B 267, 430-433 (2009)

18. Rudawska, A., Jacniacka, E.: Analysis for determining surface free energy uncertainty with the Owens-Wendt method. Int. J. Adhes. Adhes. 29(4), 451-457 (2009)

19. Sohbatzadeh, F., Mirzanejhad, S., Ghasemi, M., Talebzadeh, M.: Characterization of a non-thermal plasma torch in streamer mode and its effect on polyvinyl chloride and silicone rubber surfaces. J. Electrost. 71, 875-881 (2013)

20. Jung, M.H., Choi, H.S.: Photoresist Etching Using $\mathrm{Ar} / \mathrm{O}_{2}$ and $\mathrm{He} /$ $\mathrm{O}_{2}$ atmospheric pressure plasma. Thin Solid Films 515, 2295-2302 (2006)

21. Morent, R., De Geyter, N., Verschuren, J., Clerck, K.De, Kiekens, P., Leys, C.: Non-thermal plasma treatment of textiles. Surface Coat. Technol. 202(14), 3427-3449 (2008) 